\title{
Escola. Escala de conciencia lectora
}

\author{
Autores \\ Puente Ferreras, $A$., \\ Jiménez Rodríguez, \\ V. y Alvarado I., J. \\ Editado por EOS, Madrid
}

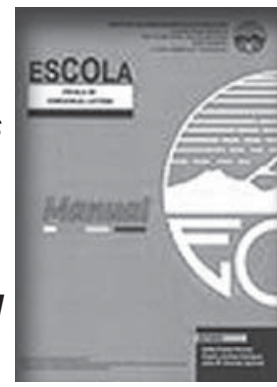

Reseña realizada por: Elena Lorente Rodríguez. Dpto. Psicología Básica II (Procesos Cognitivos).

Escuela Universitaria de Trabajo Social. Universidad Complutense de Madrid.

La metacognición es la toma de conciencia de los procesos de aprendizaje propios, de su funcionamiento y de cómo optimizar su rendimiento. Hoy en día no sólo es una habilidad cognitiva importante, sino una exigencia formativa de los planes educativos. Se plasma en la actividad educativa cotidiana como programas de "aprender a aprender". Sin embargo, se requiere de una valoración adecuada, fiable y válida de estos procesos para saber en qué áreas hay que entrenar al alumno para optimizar su rendimiento.

Se soluciona gran parte de estas dificultades gracias a este test: ESCOLA, que valora la conciencia lectora, es decir, cuán de eficaz soy como lector, cómo percibo y me ajusto a la dificultad de la tarea, si cuento con recursos para resolverla, qué estrategias pongo en funcionamiento, y así poder evaluar mi progreso y producción de lectura. Todo ello se apoya en los tres procesos de metacognición: planificación, supervisión y evaluación, que quedan recogidos de esta manera en la prueba, constituyendo tres subescalas con su puntuación delimitada.

Así se puede valorar cuál de estos procesos requiere un mayor entrenamiento en el alumno para optimizar su rendimiento lector. Una mala competencia lectora le afectará significativamente no sólo para la lectura de textos lúdicos, sino para los temas tratados en el aula, y para su futuro como estudiante: los textos a los que se enfrenta son cada vez más complejos y, por tanto, le requerirán un mayor y más eficiente empleo de estrategias de competencia lectora. Y será más negativo aún no ser consciente de que su competencia lectora no es la deseable y que le está perjudicando el rendimiento escolar y el comprender los textos que lee en su vida cotidiana: lectura de las noticias del periódico, comprensión de un cartel de aviso, lectura de formularios, publicidad gráfica, etc. Al mismo tiempo, esos procesos se combinan con tres variables: persona, tarea y texto. La variable persona, evalúa la conciencia y características de la propia persona como lector. La tarea implica conocer la amplitud de ésta y el grado de dificultad estimado. El texto como variable mide el grado de conciencia que los lectores poseen acerca de la naturaleza, características y estructura de los textos que los niños leen. Un componente importante de entrenamiento metacognitivo es el estratégico, que recorre tanto las variables antes mencionadas como los procesos participantes en la tarea de lectura. La reflexión y puesta en marcha de las estrategias facilita la obtención de metas de aprendizaje y la resolución de problemas. También se valora otra dimensión transversal esencial en los procesos metacognitivos y en la conciencia lectora, como es la motivación, porque se hace reflexionar en varios ítems acerca de si el interés que despierta el texto influye o no en la mejor comprensión de éste. Se une este aspecto a la autorregulación del aprendizaje y a su relación con las atribuciones causales del rendimiento en diferentes tareas, que es un factor importante en la aplicación de estrategias metacognitivas: dificultad de la tarea, esfuerzo, suerte, y si son factores controlables o incontrolables, que son las dimensiones clásicas de atribución causal.

La edad de aplicación de la prueba es entre 8 y 13 años, que es el período crítico de desarrollo de la metacognición. Desde una visión neuropsicológica del tema de Metacognición, se enlazaría con el concepto de Funciones Ejecutivas. La literatura define a éstas, como las capacidades que permiten a una persona participar exitosamente de un comportamiento independiente, propositivo y autorregulado. 
Ese término parece incorporar conceptos como los siguientes: volición y acción intencionada orientada a una meta; inhibición y resistencia a la distracción; solución de problemas y desarrollo, selección y monitorización de estrategias; cambio flexible de acciones para satisfacer las demandas de la tarea; mantener la persistencia hacia el alcance de la meta, y autoconciencia a través del tiempo. Estas capacidades se solapan con otras como autorregulación del comportamiento y memoria de trabajo, esencial esta última para una adecuada comprensión lectora.

Por ello, en el desarrollo de las Funciones Ejecutivas, el período entre los 6 y los 8 años es el dedicado a la autorregulación del comportamiento, fijación de metas y anticipación de eventos, pero la planificación no está tan lograda, ya que el niño tiene aún una cierta impulsividad que irá controlando paulatinamente. Hacia los 13 años el cerebro ya es como el de un adulto, y es el momento de inicio de las operaciones formales y el razonamiento abstracto, que está más allá de un razonamiento concreto de causa-efecto. Es realmente a los 16 años cuando surge el mayor desarrollo de las operaciones formales y por ende de las Funciones Ejecutivas.

En esta prueba, ese paso del razonamiento concreto al abstracto queda reflejado en las alternativas de respuesta a cada ítem y su puntuación. Una puntuación de 0 muestra un procedimiento erróneo y nada eficiente para una buena competencia lectora. Responder con la alternativa valorada con un punto corresponde a una estrategia basada en el razonamiento concreto, habitual y correcto en niños en periodo de tránsito del pensamiento concreto al pensamiento abstracto, un pensamiento más elaborado y consciente. Conseguir dos puntos en la respuesta a un ítem supone que la estrategia empleada es la correcta para una buena competencia lectora. La edad cronológica no siempre se corresponde con la edad mental, de ahí que algunos niños de 10 años puedan obtener puntuaciones que sobrepasan las expectativas. Con el test ESCOLA se supera una importante limitación psicométrica de los métodos tradicionales para valorar metacognición: el procedimiento de informes verbales o pensamiento en voz alta donde influyen la objetividad del examinador así como el vocabulario del examinado. Estos factores sesgan la opinión sobre la respuesta de los sujetos y plantea problemas con la fiabilidad y la validez de los informes.

La corrección y puntuación se hace obteniendo perfiles por los tres procesos de planificación, supervisión y evaluación tomados de forma global, o desglosando cada uno de ellos en las variables de persona, tarea y texto. De este modo se pueden obtener unos perfiles que indican en qué tipo de proceso es el que tiene un mejor rendimiento y cuál es el que requiere de un entrenamiento en estrategias metacognitivas de conciencia lectora. Es decir, entrenar para ser un lector eficiente y ser consciente de ese grado de eficiencia en la lectura.

ESCOLA es una prueba con una gran utilidad en el campo educativo, pero que puede ser empleada con otras poblaciones de forma exitosa. Obviando la población a la que está dirigida esta prueba, se podría utilizar con otras poblaciones con menor rendimiento per se en tareas de razonamiento abstracto, como son las personas mayores y los pacientes con patología psiquiátrica. Por sus características, tienen mayor dificultad en las tareas de razonamiento abstracto, por lo que no habría un efecto techo si se aplica a alguna muestra de estas dos poblaciones. También sucede entre las personas mayores con un nivel de escolarización menor que en generaciones posteriores, y que a priori no han alcanzado las operaciones formales, apoyando también esta sugerencia de uso de esta prueba en otras poblaciones. Del mismo modo, se podrían emplear los resultados en ESCOLA para orientar un programa de Rehabilitación de las Funciones Ejecutivas o uno de Psicoestimulación orientado a capacidades metacognitivas en lectura.

Además, si analizamos las dificultades de razonamiento abstracto que puede haber en la población general adulta, puede haber un importante grupo que no alcance un nivel adecuado en la realización de esta prueba. Los programas de "aprender a aprender" son relativamente nuevos en nuestro sistema educativo, ya que la generación que siguió a la ley educativa del 70 y generaciones anteriores, no fue (o fuimos) instruida en esas competencias metacognitivas de forma deliberada, sino que las desarrollamos de forma espontánea y con un método simple de aprendizaje como es el ensayo-error. La puesta en práctica de la metodología innovadora que abandera una prueba como ESCOLA, que no se queda sólo en la valoración, sino que propone formas de entrenamiento en procesos metacognitivos y cómo optimizarlos, nos permite contar con un instrumento muy recomendable aplicable a niños de 8 a 13 años y a otras poblaciones con disfunciones ejecutivas y cognitivas. 